\title{
Effect of 3-Nitroacetophenone on Corrosion Inhibition of Mild Steel in Acidic Medium
}

\author{
Sani Ibrahim, ${ }^{1,2}$ R. Sanmugapriya, ${ }^{1}$ J. Arockia Selvi $\left(\mathbb{D},{ }^{1}\right.$ T. Pushpa Malini $\left(\mathbb{D},{ }^{1}\right.$ P. Kamaraj ${ }^{3}{ }^{3}$ \\ P. A. Vivekanand $\mathbb{D}^{4}{ }^{4}$ Govindasami Periyasami ${ }^{D},{ }^{5}$ Ali Aldalbahi ${ }^{D},{ }^{6}$ Karthikeyan Perumal, ${ }^{5}$ \\ J. Madhavan $\left(\mathbb{D},{ }^{7}\right.$ and Santosh Khanal ${ }^{8}{ }^{8}$
}

${ }^{1}$ Department of Chemistry, SRM Institute of Science \& Technology, Kattankulathur, 603203 Tamil Nadu, India

${ }^{2}$ Zamfara State College of Education Maru, P.M.B 1002 Maru, Zamfara, Nigeria

${ }^{3}$ Department of Chemistry, Bharath Institute of Higher Education and Research, Chennai 600073, India

${ }^{4}$ Department of Chemistry, Saveetha Engineering College, Thandalam, Chennai 602105, India

${ }^{5}$ Department of Chemistry, College of Science, King Saud University, P.O. Box 2455, Riyadh 11451, Saudi Arabia

${ }^{6}$ Department of Chemistry and Biochemistry, The Ohio State University, 151 W. Woodruff Ave, Columbus, OH 43210, USA

${ }^{7}$ Department of Chemistry, Thiruvalluvar University, 632115, Vellore, India

${ }^{8}$ Central Department of Chemistry, Tribhuvan University, Kirtipur Kathmandu, Nepal

Correspondence should be addressed to J. Arockia Selvi; arockiaselvi29@yahoo.co.in and Santosh Khanal; santoshkhanal2003@yahoo.com

Received 27 November 2021; Revised 12 January 2022; Accepted 17 January 2022; Published 16 February 2022

Academic Editor: Bharath Govindan

Copyright (C) 2022 Sani Ibrahim et al. This is an open access article distributed under the Creative Commons Attribution License, which permits unrestricted use, distribution, and reproduction in any medium, provided the original work is properly cited.

\begin{abstract}
Acetophenone derivatives are eco-friendly corrosion inhibitors to prevent corrosion of mild steel (MS) in acidic medium. In this work, the inhibition effect of 3-nitroacetophenone (3-NA) on the corrosion of MS in acidic medium (1 N HCl) was investigated using weight loss measurements, electrochemical measurements, scanning electron microscopy, energy-dispersive X-ray spectroscopy, and quantum chemistry analysis. The studies were performed using different concentrations of inhibitors and at different temperatures. The results indicated that the inhibition efficiency of 3-NA increases with an increase in inhibitor concentration and reaches to a maximum of $64 \%$ at inhibitor concentration of $250 \mathrm{ppm}$ at $30^{\circ} \mathrm{C}$. The potentiodynamic polarization measurement indicated that 3-NA acts as mixed category of interdict. The adsorption of 3-NA on MS surface followed the Langmuir adsorption isotherm. The mode of adsorption of 3-NA on MS surface was further studied by quantum chemical calculations based on density functional theory (DFT). The results plainly revealed that 3-NA performs fairly as corrosion interdict for MS in acidic medium.
\end{abstract}

\section{Introduction}

Mild steel (MS) is widely used in infrastructural construction and has gained popularity due to its mechanical properties, malleability, toughness, availability, and low cost. It is substantially applied in different industries for different purposes which comprise production of pipelines, metal tanks, gas cylinders, and heat exchangers. MS plays a significant role in human civilization and sustainable development, so undesirable degradation due to corrosion is a big issue. Corrosion of MS considerably affects the industrial and natural environments, and development of suitable methods for corrosion control is necessary. The use of organic and inorganic inhibitors is the finest approach to shield mild steel from corrosion, specifically in acidic conditions. Inhibitors are chemical substances that can successfully impede the metal corrosion in a corrosive environment, and several organic and inorganic compounds with electron-donating substituents are used as an effective corrosion inhibitor in various industries [1].

Acetophenone is used in industry as a solvent for plastics and resins, as a catalyst for polymerization of olefins and as a photosensitizer in organic synthesis. Acetophenone is also used as an anesthetic agent to induce analgesia and also as a hypnotic agent [2]. Acetophenone compounds are a 


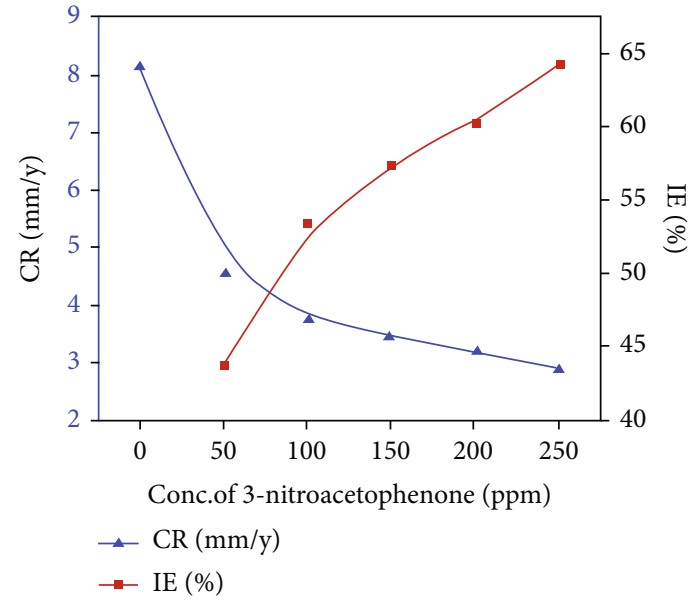

Figure 1: Corrosion rates and inhibition efficiencies of 3-NA from weight loss measurements.

successful class of compounds for bioreduction using CRED enzymes [3]. Also, acetophenones and their derivatives are known to act as corrosion inhibitors in aggressive media [4-7].

Acetophenone derivative was chosen for this study due to electron density and electron withdrawing and donating nature of the substituent group. To control corrosion of the metal, its surface needs to be masked significantly with an organic or an inorganic interdict material to be segregated from corrosive territory or domain [8-10]. Application of molecules as an interdict species is the finest and most reliable practical technique to shield the metal from dissipation in an acidic medium [11-13]. It was reported that 4aminoacetophenonepyridine 2-aldehyde (4AAPA) inhibits the corrosion of the mild steel in $1 \mathrm{~N} \mathrm{HCl}$ and maximum inhibition of $91 \%$ was achieved at a concentration of $60 \mathrm{ppm}$ [14].

In this study, the inhibition effect of 3-nitroacetophenone (3-NA), as an organic inhibitor on MS in $1 \mathrm{~N} \mathrm{HCl}$, was studied via weight loss measurement, open circuit potentials, potentiodynamic polarization studies, and electrochemical impedance spectroscopy (EIS). The hydrophobicity of the MS specimen was determined through contact angle measurement, and molecular parameters were studied by quantum chemical calculations based on density functional theory (DFT). Surface morphologies and elemental composition of MS were investigated by scanning electron microscopy (SEM) and energy-dispersive $\mathrm{X}$-ray spectroscopy (EDX), respectively.

\section{Experimental}

2.1. Materials. MS sample specimen was purchased from the local market in Chennai. The composition of the MS was carbon $(0.160 \%)$, manganese $(0.845 \%)$, sulphur $(0.007 \%)$, silicon (0.050\%), phosphorus (0.024\%), and iron (98.7\%). 3-NA and hydrochloric acid were supplied by Sigma-Aldrich. Different concentrations of $3-\mathrm{NA}(50 \mathrm{ppm}, 100 \mathrm{ppm}, 150 \mathrm{ppm}$, $200 \mathrm{ppm}$, and $250 \mathrm{ppm}$ ) were prepared in deionized water, and $1 \mathrm{~N} \mathrm{HCl}$ solution was used as corroding electrolyte.

2.2. Surface Preparation of MS Specimen. The MS $\left(1 \times 1 \mathrm{~cm}^{2}\right)$ specimens were abraded successfully with an emery sheet of different grades (600-1200 grade) until the surface was mirror polished, degreased with trichloroethylene, dried, and placed in a desiccator. Finally, the smooth and clean specimen was immersed in the solution.

2.3. Weight Loss Measurements. The inhibition efficiency of 3-NA was investigated by weight loss measurement. The weight of abraded MS sample was recorded with four-digit analytical balance before and after immersion in $100 \mathrm{~mL}$ of $1 \mathrm{~N} \mathrm{HCl}$ and $1 \mathrm{~N} \mathrm{HCl}+$ different concentrations of 3-NA for $1 \mathrm{~h}$. The effect of temperature on corrosion inhibition was studied using $250 \mathrm{ppm} 3-\mathrm{NA}$ at $303 \mathrm{~K}, 313 \mathrm{~K}, 323 \mathrm{~K}$, and $333 \mathrm{~K}$, respectively. MS samples were washed with water, rinsed with acetone, dried in air, and weighed after each measurement. Corrosion rate $(\mathrm{CR})$, surface coverage $(\theta)$, and inhibition efficiency (IE \%) were calculated using the following formula. The experiments were performed in triplicate, and average values are reported.

$$
\mathrm{CR}=\frac{87.6 \mathrm{~W}}{A \cdot d \cdot t},
$$

where $W, A, d$, and $t$ represent weight loss in $\mathrm{mg}$, surface area in $\mathrm{cm}^{2}$, and density in $\mathrm{g} \mathrm{cm}^{-3}$ of MS sample, and time of immersion in hour, respectively. The geometric surface coverage $(\theta)$ is given by

$$
\theta=\frac{W_{1}-W_{2}}{W_{1}},
$$

where $W_{1}$ and $W_{2}$ are weight loss of the MS sample in $1 \mathrm{~N} \mathrm{HCl}$ and $1 \mathrm{~N} \mathrm{HCl}+3-\mathrm{NA}$, respectively. Finally, inhibition efficiency is calculated as

$$
\operatorname{IE}(\%)=\frac{W_{1}-W_{2}}{W_{1}} \times 100 .
$$

2.4. Electrochemical Measurements. The electrochemical measurements were carried out in Ivium Vertex potentiostat/galvanostat/ZRA with Ivium soft electrochemistry software, using an electrochemical cell assembled with three electrode cells. All measurements were performed with $300 \mathrm{~mL}$ of solution using a three-electrode system. A polished MS sample with surface area $1 \mathrm{~cm}^{2}$ was employed as working electrode, the saturated calomel electrode (SCE) as reference electrode, and platinum electrode as counter electrode. The MS samples were immersed in the test solution for $15 \mathrm{~min}$ to attain a stable open circuit potential (OCP) before each polarization measurement. Potentiodynamic polarization (PDP) was recorded from $-250 \mathrm{mV}$ to $+250 \mathrm{mV}$ vs. OCP with a scan rate of $1 \mathrm{mV} \mathrm{s}^{-1}$. The cathodic and anodic slopes were determined from corresponding polarization curves. The corrosion potential $\left(E_{\text {corr }}\right)$ and corrosion current $\left(i_{\text {corr }}\right)$ were determined from Tafel extrapolation method, and corrosion inhibition efficiency (IE) was calculated by using the formula

$$
\mathrm{IE}(\%)=\frac{i_{\text {corr }}^{\circ}-i_{\text {corr }}}{i_{\text {corr }}^{\circ}} \times 100,
$$


TABLE 1: Corrosion rate $(\mathrm{mm} / \mathrm{y})$ and inhibition efficiency obtained from weight loss measurements for MS specimen in the absence and presence of 0-250 ppm concentrations of 3-NA inhibitor in acidic medium $(1 \mathrm{~N} \mathrm{HCl})$.

\begin{tabular}{lcccccc}
\hline Conc. $(\mathrm{ppm})$ & Blank $(1 \mathrm{~N} \mathrm{HCl})$ & 50 & 100 & 150 & 200 & 250 \\
\hline Weight loss $(\mathrm{g})$ & 0.0073 & 0.0041 & 0.0034 & 0.0031 & 0.0029 & 0.0026 \\
Corrosion rate $(\mathrm{mm} / \mathrm{y})$ & 8.1259 & 4.5695 & 3.7893 & 3.455 & 3.2321 & 2.8977 \\
Surface coverage $(\theta)$ & - & 0.4384 & 0.5342 & 0.5753 & 0.6027 & 0.6438 \\
Inhibition efficiency $(\%)$ & - & 43.84 & 53.42 & 57.53 & 60.27 & 64.38 \\
\hline
\end{tabular}

where $i_{\text {corr }}^{\circ}$ and $i_{\text {corr }}$ are the corrosion current densities in the absence and presence of inhibitors, respectively.

The electrochemical impendence measurements were carried out using an $\mathrm{AC}$ signal of $10 \mathrm{mV}$ amplitude in a frequency range $100 \mathrm{kHz}$ to $0.01 \mathrm{~Hz}$. The value of charge transfer resistance $\left(R_{\mathrm{t}}\right)$ was obtained from the diameter of Nyquist plots, and IE was calculated using the following relation:

$$
\operatorname{IE}(\%)=\frac{R_{\mathrm{t}}-R_{\mathrm{t}}^{\circ}}{R_{\mathrm{t}}} \times 100,
$$

where $R_{\mathrm{t}}^{\circ}$ and $R_{\mathrm{t}}$ are the charge transfer resistance for MS sample in the absence and presence of inhibitors, respectively.

2.5. SEM-EDX Analysis. MS specimens were exposed to $1 \mathrm{~N}$ $\mathrm{HCl}$ in the absence and presence of 3-NA inhibitor for $1 \mathrm{~h}$. The MS samples were eroded, degreased with trichloroethylene, and dried, and surface morphology and elemental composition were carried out by a scanning electron microscope (SEM) coupled with an energy-dispersive X-ray spectrometer (SNE 3200M, SEC).

2.6. Contact Angle Measurements. The water contact angles (WCA) of the MS surface were measured by contact angle meter KYOWA DMs-40, following sessile drop method using half-angle fitting method and FAMAS (interFAce Measurement and Analysis System) software. The volume of water droplet of $2 \mu \mathrm{L}$ was placed on MS surfaces. The measurements were repeated 10 times.

2.7. Computational Studies. Corrosion inhibition efficiency (\%) is more correlated with the molecular structure of the inhibitors. Thus, the molecular structure of 3nitroacetophenone was optimized by the density functional theory (DFT) with B3LYP correlation functional $[15,16]$ and the 6-31 G (d,p) basis set. Quantum chemical calculations were carried out using Gaussian 16 software [17]. The ionization potential $(I)$ and electron affinity $(A)$ are defined by $I=-E_{\mathrm{HOMO}}$ and $A=-E_{\mathrm{LUMO}}$, respectively. The electronegativity $\chi=I+A / 2$ and global hardness $\gamma=I-A$ / 2 are calculated. Then, the $\Delta N$ value can be calculated according to [18]

$$
\Delta N=\frac{\chi_{\mathrm{Fe}}-\chi_{\mathrm{inh}}}{2\left(\gamma_{\mathrm{Fe}}+\gamma_{\mathrm{inh}}\right)}
$$

where $\chi_{\mathrm{Fe}}=7.0 \mathrm{eV}$ and $\gamma_{\mathrm{Fe}} \approx 0$ for iron are quoted from literature.

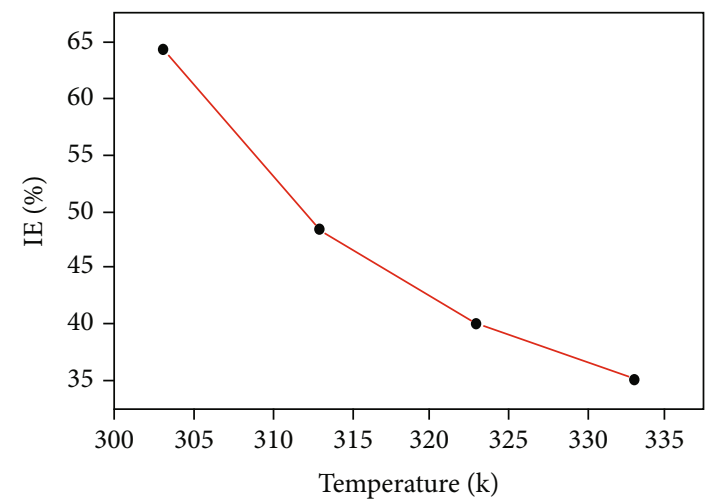

FIgURE 2: Inhibition efficiency of $250 \mathrm{ppm}$ of 3 -NA in $1 \mathrm{~N} \mathrm{HCl}$ for MS in temperature ranging from 303 to $323 \mathrm{~K}$.

\section{Results and Discussion}

3.1. Weight Loss Measurements. The abraded MS specimens were immersed in the solution $(1 \mathrm{~N} \mathrm{HCl}$ with various concentrations of the inhibitor) for 1 hour, and corrosion rate (CR) and inhibition efficiency (IE) were calculated and the results are shown in Figure 1 and Table 1. It is evident that the corrosion rate decreases with an increase in the concentration of the 3-NA and the inhibition efficiency increases with an increase in the concentration of the inhibitors which indicated that there is a substantial surface coverage by the interdict and strong bonding to surface of the mild steel.

3.1.1. Effect of Temperature. It is well known that the rate of chemical reaction increases with the increase of temperature, and then, desorption of 3-NA on MS surface occurs on increasing temperature [14]. It is also revealed that the propensity of an organic corrosion inhibitor to shield MS is via the formation of an adherent common monomolecular layer of the metal surface [14]. The effect of temperature on corrosion rate and inhibition efficiency is shown in Figure 2, and data are tabulated in Table 2 . The results suggested that the inhibition efficiency of 3-NA gradually decreased on increasing temperature from $303 \mathrm{~K}$ to $333 \mathrm{~K}$ in an inhibitor concentration of $250 \mathrm{ppm}$. This is due to desorption of 3-NA from the MS surface.

3.2. Electrochemical Impedance Spectroscopy (EIS). The electrochemical impedance spectroscopy technique was used to find the inhibition efficiency of acetophenone derivatives 
TABLE 2: Corrosion rate and inhibition efficiency obtained from weight loss measurements for MS specimen at different temperatures in the absence and presence of $250 \mathrm{ppm}$ concentration of 3-NA inhibitor in an acidic medium $(1 \mathrm{~N} \mathrm{HCl})$.

\begin{tabular}{lccccc}
\hline Temperature (K) & 303 & 313 & 323 & 333 \\
\hline Blank (1 N HCl) & CR (mm/y) & 8.1259 & 14.1542 & 16.1695 & 22.1221 \\
3-Nitroacetophenone (250 ppm) & CR (mm/y) & 4.5694 & 5.4610 & 7.0214 & 8.2473 \\
Inhibition efficiency (\%) & IE (\%) & 64.34 & 48.42 & 40.00 & 35.08 \\
\hline
\end{tabular}

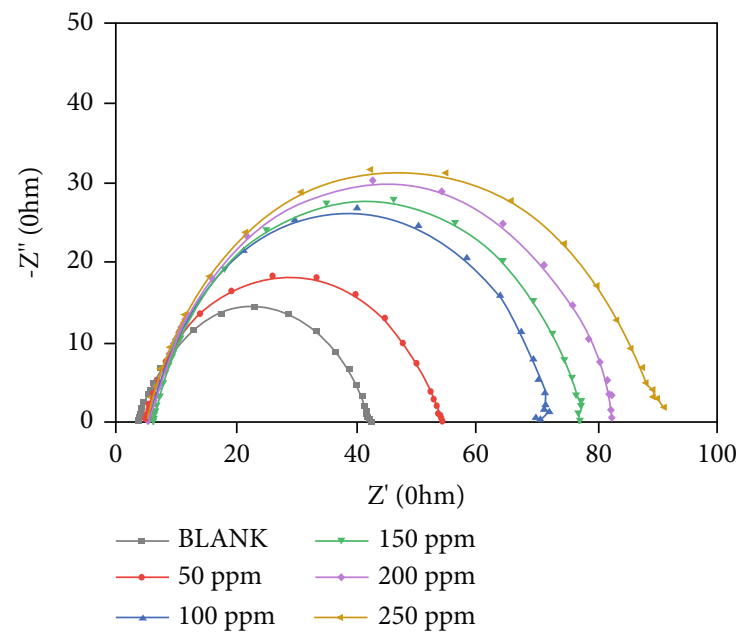

Figure 3: Nyquist plot for MS obtained with the absence and presence of 50-250 ppm of 3-NA in $1 \mathrm{~N} \mathrm{HCl}$.

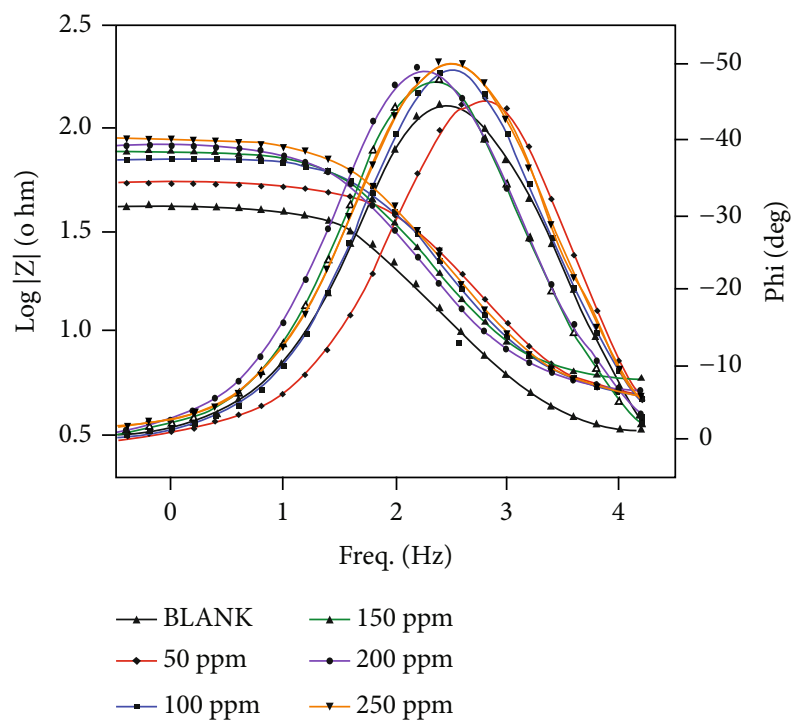

FIGURE 4: Bode plot for MS obtained with the absence and presence of 50-250 ppm of 3-nitroacetophenone in $1 \mathrm{~N} \mathrm{HCl}$.

and was accomplished in the frequency span of $100 \mathrm{kHz}$ to $0.01 \mathrm{~Hz}$. Nyquist plots and Bode plots for the MS in the absence and presence of 3-NA inhibitor at 50-250 ppm concentration in $1 \mathrm{~N} \mathrm{HCl}$ are shown in Figures 3 and 4, respectively. Table 3 shows the impedance parameters comprise of charge transfer resistance $\left(R_{\mathrm{ct}}\right)$, double layer capacitance $\left(C_{\mathrm{dl}}\right.$
TABLE 3: The EIS parameter for MS in $1 \mathrm{~N} \mathrm{HCl}$ in the presence and absence of 3-NA.

\begin{tabular}{lccc}
\hline Conc. of inhibitor $(\mathrm{ppm})$ & $R_{\mathrm{ct}}\left(\mathrm{ohm} \cdot \mathrm{cm}^{2}\right)$ & $C_{\mathrm{dl}}\left(\mathrm{F} \mathrm{cm}^{-2}\right)$ & $\mathrm{IE}(\%)$ \\
\hline Blank 1 N HCl & 38.45 & $2.6129 \times 10^{-5}$ & - \\
$50 \mathrm{ppm}$ & 49.08 & $2.0468 \times 10^{-5}$ & 21.7 \\
$100 \mathrm{ppm}$ & 64.64 & $1.5542 \times 10^{-5}$ & 40.5 \\
$150 \mathrm{ppm}$ & 71.99 & $1.3955 \times 10^{-5}$ & 46.58 \\
$200 \mathrm{ppm}$ & 77.58 & $1.2950 \times 10^{-5}$ & 50.43 \\
$250 \mathrm{ppm}$ & 86.13 & $1.1664 \times 10^{-5}$ & 55.36 \\
\hline
\end{tabular}

3-Nitroacetophenone in $1 \mathrm{~N} \mathrm{HCl}$

Figure 5: Equivalent circuit for EIS spectra of the studied system.

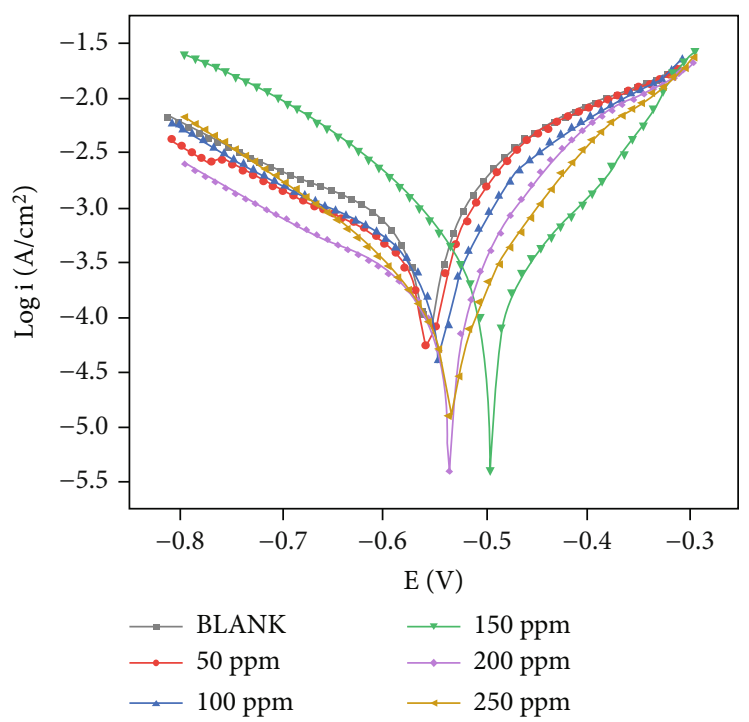

FIgURE 6: Tafel plot for MS obtained with the absence and presence of 50-250 ppm of 3-NA $1 \mathrm{~N} \mathrm{HCl}$.

), and inhibition efficiency, respectively. The increase in charge transfer resistance $\left(R_{\mathrm{ct}}\right)$ from $38.45 \mathrm{ohm} \cdot \mathrm{cm}^{2}$ (blank) to $86.13 \mathrm{ohm} \cdot \mathrm{cm}^{2}(250 \mathrm{ppm})$ revealed the formation of a 
TABLE 4: The polarization parameters for mild steel in $1 \mathrm{~N} \mathrm{HCl}$ in the presence and absence of 250 ppm of 3-nitroacetophenone.

\begin{tabular}{lccccccc}
\hline Conc. of inhibitor $(\mathrm{ppm})$ & $E_{\text {corr }}(\mathrm{V}$ vs. SCE $)$ & $i_{\text {corr }}\left(\mathrm{A} / \mathrm{cm}^{2}\right)$ & $R_{\mathrm{p}}(\mathrm{ohm})$ & $\beta_{\mathrm{a}}\left(\mathrm{V} \mathrm{dec}^{-1}\right)$ & $\left.\beta_{\mathrm{c}}(\mathrm{V} \mathrm{dec})^{-1}\right)$ & $\mathrm{CR}(\mathrm{mm} / \mathrm{y})$ & $\mathrm{IE}(\%)$ \\
\hline Blank & -0.571 & $14.02 \times 10^{-4}$ & 35.7 & 0.214 & 0.262 & 16.49 & - \\
50 & -0.573 & $11.63 \times 10^{-4}$ & 43.0 & 0.211 & 0.223 & 13.68 & 17.04 \\
100 & -0.560 & $9.59 \times 10^{-4}$ & 52.1 & 0.161 & 0.214 & 11.28 & 31.60 \\
150 & -0.498 & $5.71 \times 10^{-4}$ & 87.6 & 0.085 & 0.158 & 6.71 & 59.27 \\
200 & -0.556 & $5.04 \times 10^{-4}$ & 99.2 & 0.130 & 0.216 & 5.926 & 64.05 \\
250 & -0.545 & $3.81 \times 10^{-4}$ & 131.3 & 0.100 & 0.148 & 4.478 & 72.82 \\
\hline
\end{tabular}

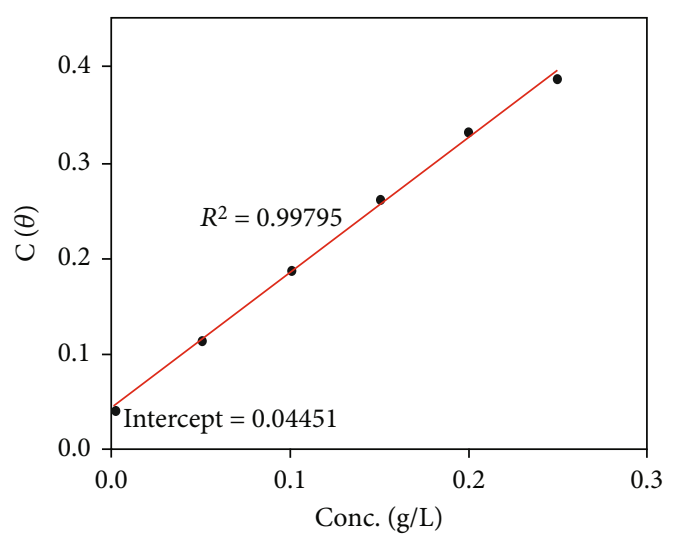

FIGURE 7: Linearized Langmuir adsorption isotherm plots of mild steel in $1 \mathrm{~N} \mathrm{HCl}$.

defensive film of 3-NA on the surface of MS by adsorption. The maximum inhibition efficiency reaches $58.5 \%$ in $3-\mathrm{NA}$ concentration of $25 \mathrm{ppm}$. The adsorption of 3-NA inhibitor on the metal surface leads to the formation of double layer, which could form a barrier between the metal surface and the corrosive medium. This is further confirmed by the decrease in the double layer capacitance $\left(C_{\mathrm{dl}}\right)$ from 2.6129 $\times 10^{-5} \mathrm{~F} \mathrm{~cm}^{-2}$ (blank) to $1.1664 \times 10^{-5} \mathrm{~F} \mathrm{~cm}^{-2}$ (250 ppm of $3-N A)$. The impedance increases with an increase in the concentration of 3-NA. Nyquist and Bode plots confirmed the single charge transfer process in corrosion inhibition mechanism. The EIS spectra obtained for mild steel were best fitted with the equivalent circuit as shown in Figure 5, where $R 1$ is the solution resistance, $R 2$ is the polarization resistance, and $C 1$ is the double layer capacitance. The $R$ (CR) model is used for the protective isolated layer formed at the metal surface and that provides a protective performance by 3-NA.

3.2.1. Potentiodynamic Polarization Study. The potentiodynamic polarization measurements were studied to investigate the effect of 3-NA on the anodic and cathodic reactions on corrosion phenomenon. The saturated calomel electrode (SCE) was used as reference electrode, mild steel with a surface area of $1 \mathrm{~cm}^{2}$ was used as working electrode, platinum electrode was used as counter electrode, and 3nitroacetophenone inhibitor in $1 \mathrm{~N} \mathrm{HCl}$ was used as electrolyte mixture. The polarization curves for $\mathrm{MS}$ in $1 \mathrm{~N} \mathrm{HCl}$ solution containing different concentrations (50-250 ppm) of 3-NA are shown in Figure 6. The different parameters obtained from polarization measurements such as corrosion potentials $\left(E_{\text {corr }}\right)$ as well as kinetic values like corrosion current density $\left(i_{\text {corr }}\right)$, cathodic and anodic Tafel slopes $\left(\beta_{\mathrm{c}}\right.$ and $\left.\beta_{\mathrm{a}}\right)$, and polarization resistance $\left(R_{\mathrm{p}}\right)$ are presented in Table 4 . There are little changes in parameters for $\beta_{\mathrm{a}}$ and $\beta_{\mathrm{c}}$ upon addition of the inhibitors as compared to blank value which indicates that the inhibitor gets adsorbed on mild steel surface controlling both anodic and cathodic reactions. The inhibitor $3-\mathrm{NA}$ is a mixed type of inhibitor as the difference in corrosion potential, $E_{\text {corr }}$, between inhibitor and that of blank is less than $80 \mathrm{mV}$. The decrease in corrosion current, $i_{\text {corr }}$, from $14.02 \times 10^{-4}$ (blank) to $3.81 \times 10^{-4}(250 \mathrm{ppm}$ of $3-\mathrm{NA})$ is observed and exhibits $72.82 \%$ IE.

3.3. Adsorption Isotherms. The adsorption isotherms are numerical utterances which give clear information on the mutual effect of the surface of the metal and adsorbing species at a constant temperature. Though there are many adsorption isotherms that give the correlation between metal surface coverage and concentration of the adsorbed species [19], the prominent adsorption isotherm is Langmuir adsorption isotherm and can be expressed via the following $[19,20]$ :

$$
\frac{C}{\theta}=\frac{1}{K_{\mathrm{ads}}}+C,
$$

where $C$ is the concentration of the inhibitor, $\theta$ is the standard degree of the surface coverage on the MS (from electrochemical impedance and polarization studies), and $K_{\text {ads }}$ is the equilibrium constant for the adsorption. The plot of $C / \theta$ vs. $C$, shown in Figure 7 , gives a straight line with a high correlation coefficient of the nearest unity and an intercept of 0.04451 , suggesting the Langmuir adsorption isotherm for adsorption of 3-NA on the MS surface. It should be noted that the adsorbed 3-NA lined up on the surface of MS to give a monolayer. $K_{\text {ads }}$ of the inhibitor was calculated using an intercept of the $C / \theta$ vs. $C$ plots and was used to calculate the free energy of adsorption $\left(\Delta G^{0}{ }_{\text {ads }}\right)$ via the following:

$$
\Delta G_{\mathrm{ads}}^{0}=-R T \ln \left(55.5 K_{\mathrm{ads}}\right),
$$



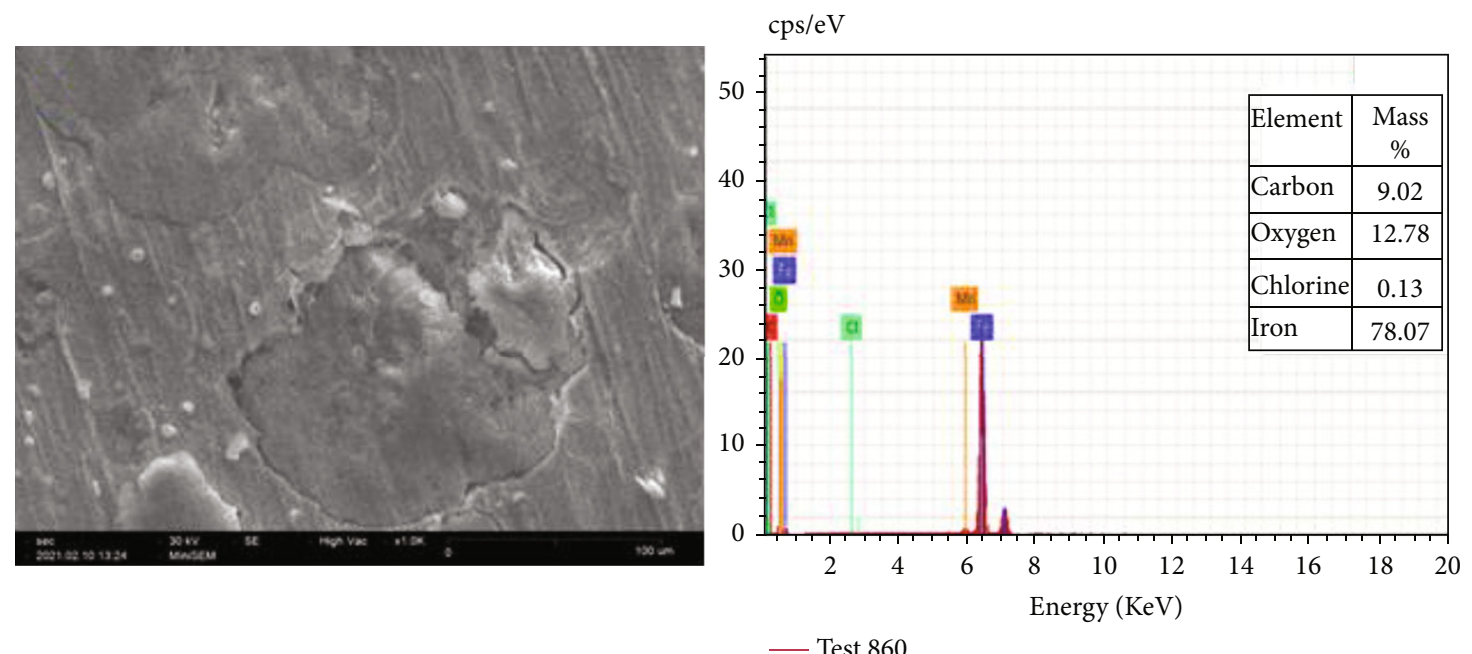

(a)
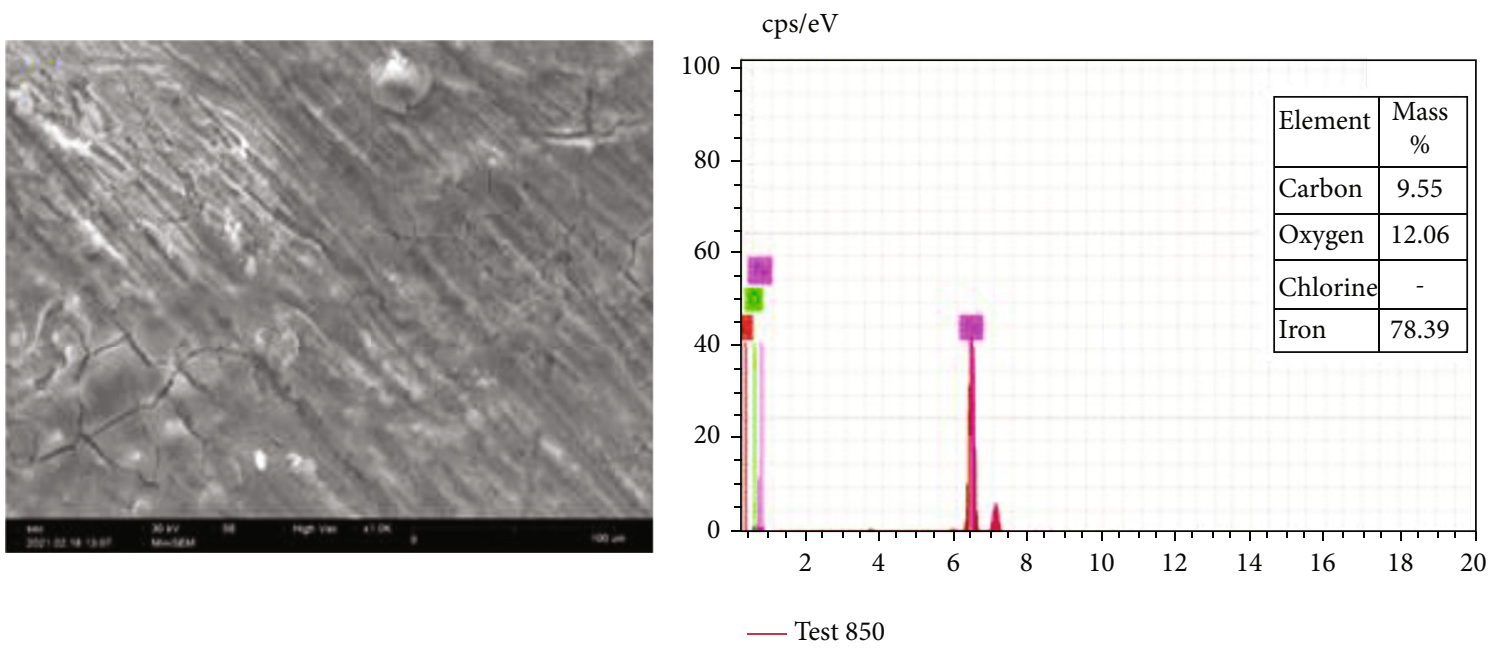

(b)

FIGURE 8: SEM-EDX micrographs of the mild steel surface: (a) in $1 \mathrm{~N} \mathrm{HCl}$ solution and (b) in $1 \mathrm{~N} \mathrm{HCl} \mathrm{solution} \mathrm{with} 250$ ppm of 3-NA.<smiles>CC(=O)c1cccc([N+](=O)[O-])c1</smiles>

FIGURE 9: Resonance structures of 3-nitroacetophenone.

where $R$ was the gas constant $\left(8.3142 \mathrm{~J} \mathrm{~K}^{-1} \mathrm{Mol}^{-1}\right)$, $T$ is the absolute temperature $(\mathrm{K})$, and 55.5 was the molar concentration of water. The adsorption parameters $K_{\text {ads }}$ and free energy of adsorption $\left(\Delta G_{\text {ads }}^{0}\right)$ are $22.47 \mathrm{Lg}^{-1}$ and $-17.96 \mathrm{~kJ} \mathrm{~mol}^{-1}$, respectively. The negative value of the standard free energy of adsorption indicates that the adsorption of 3-NA molecule on the MS surface is spontaneous. The values of $\Delta G^{0}$ ads obtained $\left(-17.96 \mathrm{~kJ} \mathrm{~mol}^{-1}\right)$ are less than
$20 \mathrm{~kJ} \mathrm{~mol}^{-1}$ which reveals the physical adsorption of 3-NA due to electrostatic communication between charged particles and charged metal.

3.4. SEM-EDX Analysis. The surface morphology of the MS specimen was evaluated by a scanning electron microscope, which gives the nature of the film formed on the MS surface. It is suggested that surface roughness is increased on attacking metal surface by aggressive media [21, 22]. SEM images are shown in Figure 8. It is observed that the MS surface is uniform before the immersion in $1 \mathrm{~N} \mathrm{HCl}$ and the surface is damaged after immersion in acid solution (Figure 8(a)). However, in the presence of $3-\mathrm{NA}$ at a concentration of $250 \mathrm{ppm}$, the surface of MS is smooth and less damaged (Figure 8(b)), which suggests that the surface of the MS is shielded and protected by 3 -NA and a good corrosion inhibition efficiency is increased. The absence of chlorine in EDX of the inhibited metal surface suggests the formation of a protective layer by the inhibitor, which prevents the 


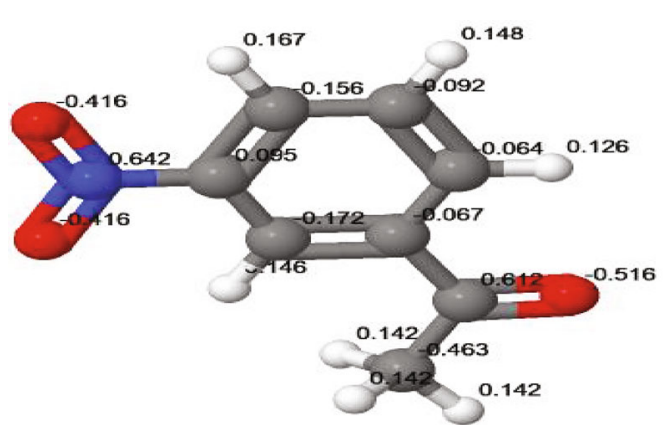

(a)

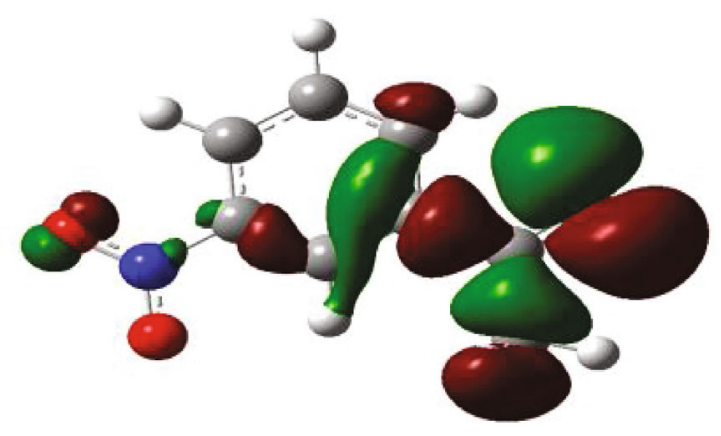

(c)

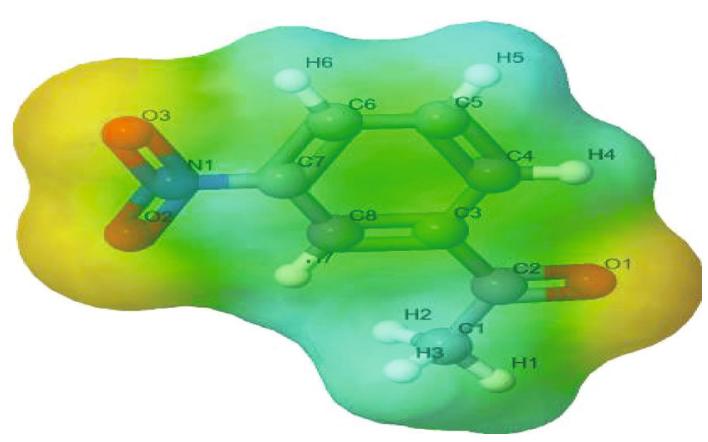

(b)

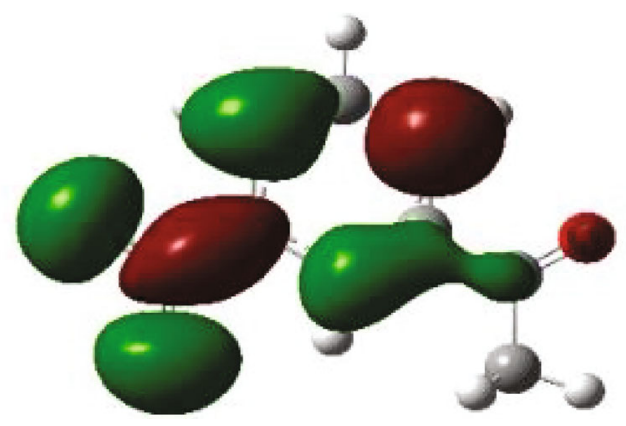

(d)

Figure 10: (a) Optimized structure, (b) electrostatic potential, (c) HOMO, and (d) LUMO of 3-nitroacetophenone.

attack of $\mathrm{Cl}^{-}$towards the metal surface. However, the surface of the metal is not fully covered by the inhibitor, as is evident from the higher mass $\%$ of $\mathrm{Fe}$ as shown in the table.

3.5. Computational Studies. The resonance structure of 3NA is shown in Figure 9, and the optimized molecular structure, electronic structure, and molecular orbital energy of 3NA are shown in Figure 10. The quantum chemical parameters, such as the energy of the highest occupied molecular orbital $\left(E_{\mathrm{HOMO}},-6.2767 \mathrm{eV}\right)$, energy of the lowest unoccupied molecular orbital $\left(E_{\mathrm{LUMO}},-3.8771 \mathrm{eV}\right)$, energy gap $\left(E_{\mathrm{LUMO}}-E_{\mathrm{HOMO}}, 2.3996 \mathrm{eV}\right)$, dipole moment $(1.6871 \mathrm{D})$, and ionization potential $(6.2765 \mathrm{eV})$ and electron affinity $(3.8771 \mathrm{eV})$, are obtained for 3-NA. The higher values of $E_{\text {HOMO }}$ denote the electron-donating abilities of the molecule. Also, the molecule with lower energy gap value in the range of 6.40 to $3.38 \mathrm{eV}$ shows higher inhibition efficiency [23-26]. However, the energy gap calculated in 3-NA is $2.3996 \mathrm{eV}$, which is not in the range required for better IE $\%$. The measure of electron transfer from inhibitor molecule to metal is favored, if $\Delta N>0$ [27]. Thereby, the calculated value of $\Delta N=0.8014$ for 3 -NA reveals the electrondonating ability of the inhibitor at the metal surface. The Mulliken charges on the atoms are used to analyze the adsorption center of the inhibitor; it is observed that if the atom has more negative charge, then the adsorption is more on the surface. The optimized structure of 3-NA with charges is shown in Figure 9(a). It is inferred that adsorption of inhibitor on the metal surface is through $\mathrm{O}$ atom rather than $\mathrm{N}$ atom, as greater negative charge is observed on $\mathrm{O}$ atoms. $\pi$-electrons also interact with the vacant d-orbital of metal. However, the presence of electron-withdrawing nitro group attracts the $\pi$-electrons of the aromatic ring. Thereby, this leads to a decrease in the electron density of the aromatic ring and thus shows lower inhibition efficiency of 3NA. The inhibition efficiency of 3-NA is compared with corrosion inhibition performance of other inhibitors as given in Table 5. The DFT study revealed that the nitration of corrosion inhibitor molecules led to the decrease in inhibition efficiency as the $-\mathrm{NO}_{2}$ group is a strong electron acceptor [28].

3.6. Contact Angle Measurement. The sessile drop contact angle measurements are shown in Figure 11 for (a) polished metal surface, (b) surface of mild steel immersed in $1 \mathrm{~N} \mathrm{HCl}$, and (c) an inhibited metal surface with $250 \mathrm{ppm}$ of $3-\mathrm{NA}$ in $1 \mathrm{~N} \mathrm{HCl}$. The water wetting nature of the metal surfaces was carried out on all the three metal surfaces. Generally, if WCA is smaller than $90^{\circ}$, the metal surface is hydrophilic, and if WCA is greater than $90^{\circ}$, then the metal surface is hydrophobic [31, 32]. The WCA for polished metal sample is observed at $102^{\circ}$, and since WCA is greater than $90^{\circ}$, it is hydrophobic. Furthermore, WCA of the metal surface immersed in $1 \mathrm{~N} \mathrm{HCl}$ is found at $41.2^{\circ}$. This confirms the wettability of the uninhibited metal surface and its hydrophilic nature. However, for inhibited metal surface using $250 \mathrm{ppm}$ of 3 -NA, WCA is seen at $64.2^{\circ}$ and a slight increase in WCA relatively shows the protective layer formed on the metal surface by the inhibitor. The decrease in wettability and increase in hydrophobicity confirm the protective nature of the mild steel surface from wetting. 
Table 5: Comparison of nitro compounds on inhibition efficiencies of steel in acid medium.

\begin{tabular}{|c|c|c|c|c|}
\hline S.N. & Inhibitor & Medium & Performance & Reference \\
\hline 1. & 4-Nitrobenzofuroxan & $1 \mathrm{M} \mathrm{HCl}$ & $200 \mathrm{ppm} / 55 \% \mathrm{IE}$ at $30^{\circ} \mathrm{C}$ for carbon steel & [29] \\
\hline 2. & 4-Nitro-2-mercaptobenzimidazole & Acidic medium & Quantum mechanical assignment, $80.52 \%$ & {$[28]$} \\
\hline 3. & 4-Nitro-2-methylbenzimidazole & Acidic medium & Quantum mechanical assignment, $66.80 \%$ & {$[28]$} \\
\hline 4. & 4-Nitrobenzimidazole & Acidic medium & Quantum mechanical assignment, $64.01 \%$ & {$[28]$} \\
\hline 5. & 2-Nitroacridone & $1 \mathrm{M} \mathrm{HCl}$ & $5 \mathrm{mM} / 94.96 \%$ at $25^{\circ} \mathrm{C}$ for low carbon steel & [30] \\
\hline 6. & 3-Nitroacetophenone & $1 \mathrm{~N} \mathrm{HCl}$ & $250 \mathrm{ppm} / 64.34 \%$ at $30^{\circ} \mathrm{C}$ for mild steel & This study \\
\hline
\end{tabular}

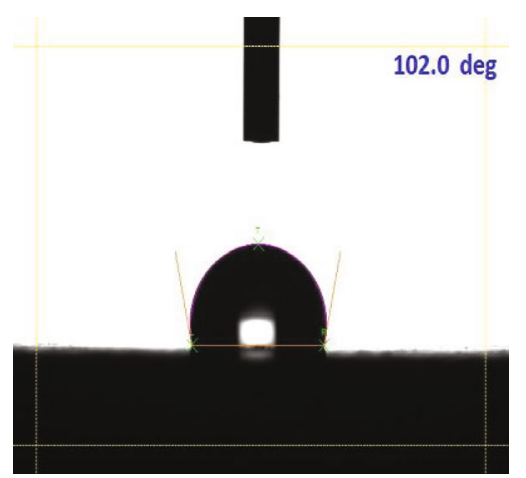

(a)

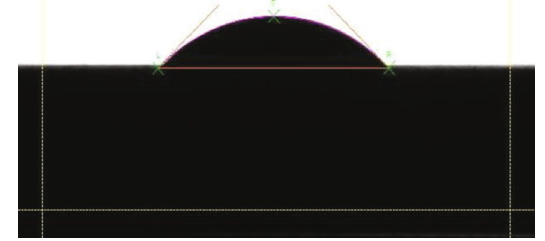

(b)

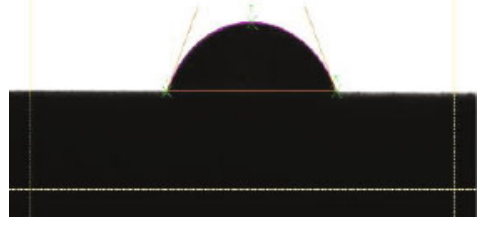

(c)

FIGURE 11: Sessile drop method: contact angle of (a) polished mild steel, (b) mild steel immersed in $1 \mathrm{~N} \mathrm{HCl}$, and (c) mild steel immersed in $250 \mathrm{ppm}$ of 3-nitroacetophenone.

\section{Conclusions}

In this study, the inhibition effect of 3-nitroacetophenone (3-NA) on the corrosion of MS in an acidic medium ( $1 \mathrm{~N}$ $\mathrm{HCl}$ ) was investigated using weight loss measurements, electrochemical measurements, and computational studies using density function theory. The results showed that 3-NA acts as mild corrosion inhibitors for $\mathrm{MS}$ in $1 \mathrm{~N} \mathrm{HCl}$ solution. The inhibition efficiency (IE) increases with the increase in concentration of 3-NA, giving maximum inhibition efficiency in $250 \mathrm{ppm}$ of 3-NA. The adsorption of 3-NA on the MS surface follows Langmuir adsorption isotherm; the value of $\Delta \mathrm{G}^{0}\left(-17.96 \mathrm{~kJ} \mathrm{~mol}^{-1}\right)$ indicates spontaneous adsorption of 3-NA by physical interaction. Polarization studies suggest that 3-NA acts as an assorted type of inhibitors. EIS studies reveal the single charge transfer process in corrosion inhibition mechanism. SEM and EDX analysis conform the formation of a protective film of 3-NA on the MS surface that inhibits the corrosion. Computational studies suggest remarkable inhibition efficiency of 3-NA and adsorption of inhibitor on the MS surface is through oxygen atom rather than nitrogen atom. However, the presence of an electronwithdrawing nitro group in 3 -NA attracts the $\pi$-electrons of the aromatic group leading to a decrease in electron density and thereby shows lower inhibition efficiency.

\section{Data Availability}

The data used to support the findings of this study are available upon request.

\section{Conflicts of Interest}

All authors declared that they have no conflicts of interest.

\section{Acknowledgments}

The authors are immensely thankful and acknowledge the Nanotechnology Research Centre (NRC), SRMIST, for providing the research facilities, SEM. We thank Dr. K.K. Ramanatha Datta, SRM IST, Functional Nanomaterials Laboratory, for contact angle measurements. They also acknowledge Dr. Renjith S. Pillai, SRM IST, for the computational studies. The authors acknowledge King Saud University, Riyadh, Saudi Arabia, for funding this work through Researchers Supporting Project number RSP-2021/30.

\section{Supplementary Materials}

Supplementary 1: the graphical abstract summarizes the entire manuscript. (Supplementary Materials)

\section{References}

[1] I. G. Mamedov, I. M. Shikhaliyeva, Y. V. Mamedova, S. Z. Gasimova, and A. M. Maharramov, "Some acetophenone derivatives as corrosion inhibitors," Chemical Problems, vol. 17, no. 2, pp. 302-309, 2019.

[2] N. V. Soucy, "Acetophenone," in Encyclopedia of Toxicology [Third Edition], P. Wexler, Ed., pp. 43-45, 2014.

[3] Thomas S. Moody and J. David Rozzell, "Modern biocatalytic ketone reduction," in Organic Synthesis Using Biocatalysis 
[First Edition], A. Goswami and J. Stewart, Eds., pp. 149-185, Elsevier, 2016.

[4] M. Bouklah, B. Hammouti, A. Aouniti, M. Benkaddour, and A. Bouyanzer, "Synergistic effect of iodide ions on the corrosion inhibition of steel in $0.5 \mathrm{M} \mathrm{H} 2 \mathrm{SO} 4$ by new chalcone derivatives," Applied Surface Science, vol. 252, no. 18, pp. 6236-6242, 2006.

[5] J. Y. Hu, X. O. Song, Z. Zhang, D. Z. Zeng, T. H. Shi, and I. F. Gao, "The corrosion inhibition behaviors of 2'-hydroxy-acetophenone for AZ91D magnesium alloy," Materials and Corrosion, vol. 66, no. 4, pp. 396-404, 2015.

[6] A. S. Fouda, K. Shalabi, G. Y. Elewady, and H. F. Merayyed, "Chalcone derivatives as corrosion inhibitors for carbon steel in $1 \mathrm{M} \mathrm{HCl}$ solutions," International Journal of Electrochemical Science, vol. 9, pp. 7038-7058, 2014.

[7] Y. Zhu, L. Zhao, P. Liu, P. Chen, and W. Tao, "Corrosion and inhibition of P110 steel in $20 \% \mathrm{HCl}$ solution by Mannich base inhibitor," International Journal of Electrochemical Science, vol. 14, pp. 1331-1341, 2019.

[8] P. Singh, M. A. Quraishi, E. E. Ebenso, and C. B. Verma, "Ultrasound assisted synthesis of chalcones as green corrosion inhibitors for mild steel in 1M hydrochloric solution," International Journal of Electrochemical Science, vol. 9, pp. 7446-7459, 2014.

[9] H. El Attari, S. Mengouch, M. Siniti, E. Zahidi, L. Khamliche, and A. Kheribech, "Quantum chemical studies and adsorption characteristics of 4-hydroxy-3-[1-(2-phenylhydrazinylidene) ethyl] 2H-1-benzopyran-2one on mild steel in hydrochloric acid," Journal of Materials and Environmental Science, vol. 2508, pp. 689-700, 2018.

[10] S. Cao, D. Liu, P. Zhang et al., "Green Bronsted acid ionic liquids as novel corrosion inhibitors for carbon steel in acidic medium," Scientific Reports, vol. 7, no. 1, pp. 1-14, 2017.

[11] Y. Meng, W. Ning, B. Xu et al., "“'Inhibition of mild steel corrosion in hydrochloric acid using two novel pyridine Schiff base derivatives": a comparative study of experimental and theoretical results," RSC Advances, vol. 7, no. 68, pp. 43014-43029, 2017.

[12] M. A. Deyab, A. S. Fouda, M. M. Osman, and S. Abdel-Fattah, "Mitigation of acid corrosion on carbon steel by novel pyrazolone derivatives," RSC Advances, vol. 7, no. 71, pp. 4523245240, 2017.

[13] H. B. Sehmi, A. Ouici, M. F. Guendouzi, O. Benali, and F. Boudjellal, "Corrosion inhibition of mild steel by newly synthesized pyrazole carboxamide derivatives in $\mathrm{HCl}$ acid medium," Journal of the Electrochemical Society, vol. 167, no. 15, p. 155508, 2020.

[14] R. Karthik, G. Vimaladevi, A. Shen-Ming Chen, B. J. Elangovan, and P. Prakash, "Corrosion inhibition and adsorption behaviour of 4-amino acetophenone pyridine 2-aldehyde in $1 \mathrm{M}$ hydrochloric acid," International Journal of Electrochemical Science, vol. 10, pp. 4666-4681, 2015.

[15] A. D. Becke, "Density-functional thermochemistry. III. The role of exact exchange," The Journal of Chemical Physics, vol. 98, pp. 5648-5652, 1993.

[16] C. T. Lee, W. T. Yang, and R. G. Parr, "Development of the Colle-Salvetti correlation-energy formula into a functional of the electron density," Physical Review B, vol. 37, no. 2, pp. 785-789, 1988.

[17] M. J. Frisch, G. W. Trucks, H. B. Schlegel et al., Gaussian 16, Revision B.01, Gaussian, Inc., Wallingford CT, UK, 2016.

[18] V. S. Sastri and J. R. Perumareddi, "Molecular orbital theoretical studies of some organic corrosion inhibitors," Corrosion, vol. 53, no. 8, pp. 617-622, 1997.
[19] A. A. Farag, A. S. Ismail, and M. A. Migahed, "Environmentalfriendly shrimp waste protein corrosion inhibitor for carbon steel in $1 \mathrm{M} \mathrm{HCl}$ solution," Journal of Petroleum, vol. 27, no. 4, pp. 1187-1194, 2018.

[20] T. K. Bhuvaneswari, C. Jeyaprabha, and P. Arulmathi, "Corrosion inhibition of mild steel in hydrochloric acid by leaves extract of Tephrosiapurpurea," Journal of Adhesion Science and Technology, vol. 34, pp. 2424-2427, 2020.

[21] V. Saraswat and M. Yadav, "Computational and electrochemical analysis on quinoxalines as corrosion inhibitors for mild steel in acidic medium," Journal of Molecular Liquids, vol. 297, p. 111883, 2020.

[22] M. M. El-Naggar, "Corrosion inhibition of mild steel in acidic medium by some sulfa drugs compounds," Corrosion Science, vol. 49, no. 5, pp. 2226-2236, 2007.

[23] M. Corrales Luna, T. le Manh, R. Cabrera Sierra, J. V. Medina Flores, L. Lartundo Rojas, and E. M. Arce Estrada, "Study of corrosion behavior of API 5L X52 steel in sulfuric acid in the presence of ionic liquid 1-ethyl 3-methylimidazolium thiocyanate as corrosion inhibitor," Journal of Molecular Liquids, vol. 289, p. 111106, 2019.

[24] C. Verma, L. O. Olasunkanmi, I. Bahadur et al., "Experimental, density functional theory and molecular dynamics supported adsorption behavior of environmental benign imidazolium based ionic liquids on mild steel surface in acidic medium," Journal of Molecular Liquids, vol. 273, pp. 1-15, 2019.

[25] E. A. M. Gad, E. M. S. Azzam, and S. A. Halim, "Theoretical approach for the performance of 4-mercapto-1-alkylpyridin1 -ium bromide as corrosion inhibitors using DFT," Egyptian Journal of Petroleum, vol. 27, no. 4, pp. 695-699, 2018.

[26] S. Fouda, M. M. Gouda, and S. I. Abd El-Rahman, "1, 2, 4Triazole on carbon steel corrosion in hydrochloric acid," Bulletin of the Korean Chemical Society, vol. 21, no. 11, 2000.

[27] Z. Cao, Y. Tang, H. Cang, J. Xu, G. Lu, and W. Jing, "Novel benzimidazole derivatives as corrosion inhibitors of mild steel in the acidic media. Part II: theoretical studies," Corrosion Science, vol. 83, pp. 292-298, 2014.

[28] H. R. Obayes, G. H. Alwan, A. H. M. J. Alobaidy, A. A. Al-Amiery, A. A. H. Kadhum, and A. B. Mohamad, "Quantum chemical assessment of benzimidazole derivatives as corrosion inhibitors," Chemistry Central Journal, vol. 8, no. 1, pp. 1-8, 2014.

[29] M. Abdallah, B. H. Asghar, I. Zaafarany, and M. Sobhi, "Synthesis of some aromatic nitro compounds and its applications as inhibitors for corrosion of carbon steel in hydrochloric acid solution," Protection of Metals and Physical Chemistry of Surfaces, vol. 49, no. 4, pp. 485-491, 2013.

[30] J. Aslam, R. Aslam, I. H. Lone et al., "Inhibitory effect of 2nitroacridone on corrosion of low carbon steel in $1 \mathrm{M} \mathrm{HCl}$ solution: an experimental and theoretical approach," Journal of Materials Research and Technology, vol. 9, no. 3, pp. 4061-4075, 2020.

[31] P. Singh, A. K. Singh, and V. P. Singh, "Synthesis, structural and corrosion inhibition properties of some transition metal(II) complexes with o-hydroxyacetophenone-2-thiophenoyl hydrazone," Polyhedron, vol. 65, pp. 73-81, 2013.

[32] H. Jafari, I. Danaee, H. Eskandari, and M. Rashvand Avei, "Electrochemical and theoretical studies of adsorption and corrosion inhibition of N, N-bis (2-hydroxy ethoxy acetophenone) 2-dimethyl-1, 2-propanediimine on low carbon steel (API 5L Geade B) in acidic medium," Industrial and Engineering Chemistry Research, vol. 52, no. 20, pp. 6617663220, 2013. 